\title{
Kidney Dysfunction Increases Mortality and Incident Events after Young Stroke: The FUTURE Study
}

\author{
Nathalie E. Synhaeve ${ }^{a}$ d $\quad$ Mayte E. van Alebeek ${ }^{a}$ Renate M. Arntz ${ }^{a}$ \\ Noortje A.M. Maaijwee ${ }^{a}$ Loes C.A. Rutten-Jacobs ${ }^{a, e}$ Henny C. Schoonderwaldt ${ }^{a}$ \\ Paul L.M. de Kort ${ }^{d}$ Maureen J. van der Vlugt ${ }^{b}$ Ewoud J. Van Dijk ${ }^{a}$ \\ Jack F.M. Wetzels ${ }^{c}$ Frank-Erik de Leeuw ${ }^{a}$ \\ a Department of Neurology, Donders Institute for Brain, Cognition and Behaviour, Centre for Neuroscience, \\ ${ }^{b}$ Department of Cardiology and ' Department of Nephrology, Radboud University Medical Center, Radboud University \\ Medical Center, Nijmegen, and ${ }^{\mathrm{d}}$ Department of Neurology, Elisabeth Hospital, Tilburg, The Netherlands; ${ }^{\mathrm{e}}$ Department \\ of Clinical Neurosciences, Neurology Unit, University of Cambridge, Cambridge, UK
}

\section{Key Words}

Stroke in young adults - Prognosis - Kidney function .

Transient ischemic attack

\begin{abstract}
Background: In about $30 \%$ of young stroke patients, no cause can be identified. In elderly patients, kidney dysfunction has been suggested as a contributing risk factor for mortality as well as stroke. There are hypotheses that novel nontraditional risk factors, like chronic inflammation and oxidative stress, are involved in chronic kidney disease, affecting the cerebral microvasculature that would in turn lead to stroke. Our objective is to investigate the influence of kidney dysfunction on long-term mortality and incident vascular events after stroke in young adults aged 18 through 50 and if this relationship would be independent of other cardiovascular risk factors. Methods: We prospectively included 460 young stroke patients with an ischemic stroke or transient ischemic attack admitted to our department between January 1, 1980 and November 1, 2010. Follow-up was done between 2014 and 2015. Estimated glomerular filtration rate
\end{abstract}

\section{KARGER}

E-Mail karger@karger.com www.karger.com/ced

\section{C) 2016 The Author(s) \\ Published by S. Karger AG, Basel 1015-9770/16/0424-0224\$39.50/0}

This article is licensed under the Creative Commons AttributionNonCommercial-NoDerivatives 4.0 International License (CC BYNC-ND) (http://www.karger.com/Services/OpenAccessLicense) Usage and distribution for commercial purposes as well as any distribution of modified material requires written permission.
(eGFR) was calculated from baseline creatinine levels and was divided in 3 subgroups: eGFR $<60,60-120$ and $>120 \mathrm{ml} /$ $\mathrm{min} / 1.73 \mathrm{~m}^{2}$. Cox proportional hazard models were used to determine the effect of kidney dysfunction on mortality and incident vascular events, adjusting for cardiovascular risk factors. Results: An eGFR <60 (HR 4.6; 95\% Cl 2.6-8.2) was associated with an increased risk of death and an increased risk of incident stroke (HR 4.1; 95\% Cl 1.9-9.0) independent of cardiovascular risk factors, but it was not associated with other vascular events. The point estimate for the 15-year cumulative mortality was $70 \%(95 \% \mathrm{Cl} 46-94)$ for patients with a low eGFR, 24\% (95\% Cl 18-30) for patients with a normal eGFR and $30 \%(95 \% \mathrm{Cl} 12-48)$ for patients with a high eGFR. The point estimate for the 15-year cumulative risk of incident stroke was $45 \%$ (95\% Cl 16-74) for patients with a low eGFR, $13 \%(95 \% \mathrm{Cl} 9-17)$ for patients with a normal eGFR and $8 \%$ (95\% Cl 0-18) for patients with a high eGFR. Conclusions: Kidney dysfunction is related to long-term mortality and stroke recurrence, but not to incident cardiovascular disease, on average 11 years after young stroke. This warrants a more intensive follow-up of young stroke patients with signs of kidney dysfunction in the early phase. In addition, 
the clear association between kidney dysfunction and incident stroke seen in our young stroke population might be a first step in the recognition of kidney dysfunction as a new risk factor for the development of stroke at young age. Also, it can lead to new insights in the etiological differences between cardiovascular and cerebrovascular disease.

(c) 2016 The Author(s)

Published by S. Karger AG, Basel

\section{Introduction}

In about $30 \%$ of young ischemic stroke (IS) patients, no cause can be identified despite an extensive diagnostic work up [1]. Recently, there has been an increase in interest in understanding the role of kidney dysfunction in the etiology and prognosis of stroke $[2,3]$ since an increased prevalence of kidney dysfunction was observed in stroke patients and was related to increased in-hospital mortality [4] and increased long-term mortality [5-7], although this trend was predominant in elderly stroke patients [8]. To date, only one study described a relationship between kidney dysfunction and increased long-term mortality and incident cardiovascular disease in a young IS population, although the relationship between kidney dysfunction and incident cardiovascular events was not found to be independent from cardiovascular risk factors [9].

In elderly patients, the traditionally held view is that stroke and kidney dysfunction share identical traditional cardiovascular risk factors, such as hypertension and diabetes mellitus, and as such kidney dysfunction could be considered a surrogate marker for cerebrovascular disease, rather than an independent risk factor for stroke. Although these traditional risk factors are less prevalent in patients with stroke at young age and they have been exposed to these risk factors for a much shorter period of time, it cannot be excluded that kidney dysfunction is, even in these young patients, just a surrogate marker of cardiovascular disease. However, there are also hypotheses that novel nontraditional risk factors, like chronic inflammation and oxidative stress, are involved in chronic kidney disease, affecting the cerebral microvasculature, which in turn could lead to stroke $[8,10]$.

As a first step in clarifying the relationship between kidney function and stroke at a young age, we wanted to investigate the relationship between kidney function at stroke onset, mortality and incident vascular events after stroke in young adults and if so, if this relationship would be independent of other cardiovascular risk factors.

Kidney Dysfunction and Outcome after Young Stroke

\section{Methods}

Patients and Study Design

This study is part of the 'Follow-Up of Transient ischemic attack and stroke patients and Unelucidated Risk factor Evaluation' (FUTURE) study, a prospective cohort study that investigates causes and consequences of a young stroke [11]. The Medical Review Ethics Committee region Arnhem-Nijmegen approved the study. Written informed consent was obtained from all patients.

In short, the FUTURE study comprised all consecutive patients with a transient ischemic attack (TIA), IS or intracerebral hemorrhage (ICH), between ages 18 and 50, admitted to the Radboud University Medical Center between January 1, 1980 and November 1, 2010. For this study, we only included patients with first-ever IS or TIA. Exclusion criteria were cerebral venous sinus thrombosis and retinal infarction. To minimize bias due to changing diagnostic techniques, the World Health Organization definition for TIA and stroke was used $[12,13]$. Stroke was defined as a rapidly evolving focal neurological deficit with no other than a vascular cause persisting for more than $24 \mathrm{~h}$. On the basis of radiological findings, stroke was subdivided into ICH and IS. TIA was defined similarly but with symptoms persisting for less than 24 h.

Patients were identified through a prospective registry of all consecutive young stroke patients that has been maintained at the department initiated in 1978 [14], with a standardized collection of baseline and clinical characteristics [11].

Cardiovascular risk factors at baseline were defined either as a history of a risk factor (mentioned in medical history or the use of medication) or as a risk factor detected during admission or during the analysis of the stroke, based on the following criteria: diabetes mellitus as a random blood glucose level $>11.1 \mathrm{mmol} / \mathrm{l}$ or 2 consecutive fasting venous plasma glucose levels of $\geq 7.0 \mathrm{mmol} / \mathrm{l}$ [15]; hypertension as systolic blood pressure $\geq 135 \mathrm{~mm} \mathrm{Hg}$, diastolic blood pressure $\geq 85 \mathrm{~mm} \mathrm{Hg}$, or both, measured after the first week of the index event; and atrial fibrillation when identified on either an electrocardiogram or during continuous electrocardiographic recording; dyslipidemia as a cholesterol level $>5.0 \mathrm{mmol}$ and/or $\mathrm{LDL}>2.5 \mathrm{mmol} / \mathrm{l}$ and/or a triglycerides of $>2.0 \mathrm{mmol} / \mathrm{l}$. Smoking was defined as smoking at least 1 cigarette per day in the year prior to the event. A history of arterial disease was defined as a history of cardiac disease, including myocardial infarction and surgical treatment for coronary artery disease, or peripheral artery disease.

Furthermore, all patients underwent a neurological examination and brain imaging at the time of their index event [16]. The assessment of both the etiology (modified Trial of ORG 10172 in Acute Stroke Treatment (TOAST) classification) [17] and severity (National Institutes of Health Stroke Scale (NIHSS) [18] at admission) was done for all cases retrospectively by a validated approach $[19,20]$, as these scales did not exist at the time when a substantial proportion of our patients experienced their qualifying event.

\section{Follow-Up}

Information on the vital status was available either from hospital data or from the municipality registry. Patients alive were invited for an extensive follow-up assessment between November 1, 2009 and January 1, 2012, which included the assessment of incident events and the evaluation of cardiovascular risk factors. Sub- 
sequently, between August 1, 2014 and January 15, 2015, TIA and IS patients alive were approached by telephone to assess incident events. Of 17 surviving patients (3.7\%), information about incident events was missing during the follow-up in 2014-2015; therefore, in these patients, follow-up data from the previous follow-up between 2009 and 2012 were used.

The occurrence of incident strokes (IS or ICH) or other arterial diseases (cardiac disease and peripheral artery disease) were assessed using a standardized, structured questionnaire. Whenever an event was suspected, information was retrieved from the treating physicians and subsequently verified by specialists from the appropriate field. If information concerning a recurrent vascular event was not sufficient to confirm the diagnosis, it was considered a possible event and not used in the analyses.

\section{Outcome}

The primary endpoint was death by any cause. Secondary outcomes included any fatal or non-fatal incident arterial event, consisting of fatal or non-fatal incident stroke (IS or ICH) and fatal or non-fatal other incident arterial disease (cardiac disease, including myocardial infarction, coronary artery bypass grafting and percutaneous coronary intervention for coronary artery disease, and peripheral artery disease) [21].

\section{Kidney Function}

We included those patients for whom creatinine level readings were available within 1 month after the event (70.1\% of the cohort). The median time between the index event and creatinine measurement was 1 day (interquartile range $0-3$ days). The Jaffe method was used for creatinine measurement until December 2005; thereafter, an enzymatic method, calibrated to IDMS traceable creatinine, was used. Jaffe values were recalculated to enzymatic values using a previously described correction factor [22-24]. Estimated glomerular filtration rate (eGFR) was calculated from baseline creatinine concentrations, using the chronic kidney disease-epidemiology collaboration (CKD-EPI) equation [25]. For patients undergoing dialysis, a constant eGFR value of $15 \mathrm{ml} / \mathrm{min} / 1.73 \mathrm{~m}^{2}$ was used $(\mathrm{n}=2)$. eGFR was divided into 3 categories: low eGFR $(<60$ $\left.\mathrm{ml} / \mathrm{min} / 1.73 \mathrm{~m}^{2}\right)$, normal eGFR $\left(60-120 \mathrm{ml} / \mathrm{min} / 1.73 \mathrm{~m}^{2}\right)$ and high eGFR ( $\left.>120 \mathrm{ml} / \mathrm{min} / 1.73 \mathrm{~m}^{2}\right)$ [9]. GFR $<60 \mathrm{ml} / \mathrm{min} / 1.73 \mathrm{~m}^{2}$ is generally regarded as impaired renal function [26]. Also, it is suggested that a GFR $>120 \mathrm{ml} / \mathrm{min} / 1.73 \mathrm{~m}^{2}$ is related to an unfavorable outcome [27]. An eGFR $>120 \mathrm{ml} / \mathrm{min} / 1.73 \mathrm{~m}^{2}$ can be regarded as hyperfiltration, which could be a sign of early kidney disease [27]. However, a high eGFR can also be caused by comorbidity.

\section{Statistical Analysis}

Univariate analysis was done to compare patients with an eGFR $<60,60-120$ and $>120 \mathrm{ml} / \mathrm{min} / 1.73 \mathrm{~m}^{2}$ on stroke subtype (TIA or IS), age, gender, cardiovascular risk factors and TOAST classification using chi-square tests or Fisher's exact tests when appropriate for categorical variables and analysis of variance or Kruskal-Wallis tests for non-parametric continuous variables. Survival plots were made for cumulative mortality, incident arterial events and incident stroke, and other arterial diseases were stratified based on kidney function. Patients who died within 30 days after the index stroke were regarded as fatal cases and were therefore excluded from the mortality analysis [11]. To ensure that the provided plots were reliable for all subgroups, survival plots were curtailed at 15 years [28]. Patients who did not reach an endpoint before followup ended were censored.

Cox proportional hazards models, adjusted for age, gender, the presence of hypertension, diabetes mellitus and/or a history of arterial disease were used to calculate the relative risks for death and any fatal or non-fatal incident arterial event for patients with a low eGFR $\left(<60 \mathrm{ml} / \mathrm{min} / 1.73 \mathrm{~m}^{2}\right)$ compared to patients with a normal eGFR $\left(60-120 \mathrm{ml} / \mathrm{min} / 1.73 \mathrm{~m}^{2}\right)$ as the reference group. Patients with a high eGFR $\left(>120 \mathrm{ml} / \mathrm{min} / 1.73 \mathrm{~m}^{2}\right)$ could not be reliably compared with patients with a normal eGFR with regard to the occurrence of incident events, since the lines in the corresponding survival plots cross each other. This means that the assumption that the effect of the different variables on the outcome is constant over time (proportional hazards assumption) was not correct; this is however essential for a cox proportional hazard model. In addition, we repeated these analyses stratified by the time of admission $(<1990,1990-2000,>2000)$, to evaluate the effect of changes in diagnostic work-up and treatment over time. Also, we repeated the analysis including only those patients who had a creatinine level available within 1 day after their index event.

At a young age, the mean GFR is substantially higher than at an older age, which could lead to the underestimation of young patients with impaired kidney function because their eGFR can be above $60 \mathrm{ml} / \mathrm{min} / 1.73 \mathrm{~m}^{2}$, while still having a substantially lower eGFR than would be expected on the basis of their age. Therefore, we analyzed our data by dividing the eGFR in 3 other categories (below the 5th percentile (p5), above the 95th percentile (p95) and between $\mathrm{p} 5$ and $\mathrm{p} 95$ of the expected eGFR of the corresponding age group based on a previous validation study of the CKD-EPI equation in our hospital) [23]. Furthermore, the analysis was repeated including only patients with an IS. $\mathrm{p}<0.05$ was considered significant. The statistical analysis was done using SPSS 20 for Windows.

\section{Results}

\section{Study Population}

Of the 809 eligible patients, 153 refused to participate, and of 196 patients, baseline creatinine levels were unavailable. Therefore, only 460 patients (322 IS, 138 TIA) with a first ever stroke could participate in the current analysis. Compared to those enrolled in the study, patients who refused to participate were slightly younger (39.1 vs. 40.7 years, $\mathrm{p}=0.008$ ); no other differences in demographics or stroke characteristics were found. Compared with patients with available baseline creatinine levels, patients without this information were slightly younger (39.6 vs. 41.2 years, $\mathrm{p}=0.010)$ and had less severe strokes (median NIHSS 2 vs. $3, \mathrm{p}<0.001$ ); no differences in any of the other baseline characteristics were found. The baseline characteristics of the study population are presented in table 1 .

After a mean follow-up of 11.5 (SD 8.3) years, 115 patients $(25.0 \%)$ had died of which 21 patients $(4.6 \%)$ were 
Table 1. Baseline characteristics

\begin{tabular}{|c|c|c|c|c|c|}
\hline & \multirow[t]{2}{*}{ Total } & \multicolumn{3}{|c|}{$\mathrm{eGFR}, \mathrm{ml} / \mathrm{min} / 1.73 \mathrm{~m}^{2}$} & \multirow[t]{2}{*}{$\mathrm{p}$ value* } \\
\hline & & $<60$ & $60-120$ & $>120$ & \\
\hline Total, n (\%) & $460(100)$ & $29(6.3)$ & $392(85.2)$ & $39(8.5)$ & \\
\hline IS patients, n (\%) & $322(70.0)$ & $22(75.9)$ & $270(68.9)$ & $30(76.9)$ & 0.449 \\
\hline Age at event, years, mean \pm SD & $41.2 \pm 7.6$ & $42.2 \pm 7.2$ & $42.1 \pm 6.9$ & $32.4 \pm 9.3$ & $<0.001$ \\
\hline Men, $\mathrm{n}(\%)$ & $218(47.4)$ & $18(62.1)$ & $178(45.4)$ & $22(56.4)$ & 0.111 \\
\hline NIHSS at admission, median (IQR) & $3(1-9)$ & $4(1-11)$ & $3(1-8)$ & $9(3-15)$ & 0.001 \\
\hline Follow-up, years, mean \pm SD & $11.5 \pm 8.3$ & $7.2 \pm 7.2$ & $11.8 \pm 8.3$ & $11.2 \pm 8.5$ & 0.009 \\
\hline \multicolumn{6}{|l|}{ TOAST, $\mathrm{n}(\%)$} \\
\hline Large artery & $107(23.3)$ & $8(27.6)$ & $93(23.7)$ & $6(15.4)$ & 0.426 \\
\hline Cardioembolism & $65(14.1)$ & $7(24.1)$ & $51(13.0)$ & $7(17.9)$ & 0.195 \\
\hline Small vessel & $51(11.1)$ & $5(17.2)$ & $44(11.2)$ & $2(5.1)$ & 0.279 \\
\hline Other determined & $68(14.8)$ & $3(10.3)$ & $60(15.3)$ & $5(12.8)$ & 0.702 \\
\hline Multiple causes & $10(2.2)$ & $2(6.9)$ & $8(2.0)$ & 0 & 0.165 \\
\hline Unknown & $159(34.6)$ & $4(13.8)$ & $136(34.7)$ & $19(48.7)$ & 0.011 \\
\hline Hypertension, n (\%) & $162(35.2)$ & $21(72.4)$ & $132(33.7)$ & $9(23.1)$ & $<0.001$ \\
\hline Diabetes mellitus, n (\%) & $38(8.3)$ & $5(17.2)$ & $29(7.4)$ & $4(10.3)$ & 0.127 \\
\hline Dyslipidemia, n (\%) & $272(80.7)$ & $18(94.7)$ & $226(79.0)$ & $28(87.5)$ & 0.144 \\
\hline Atrial fibrillation, $\mathrm{n}(\%)$ & $9(2.0)$ & 0 & $9(2.3)$ & 0 & 1.000 \\
\hline Smoking, $\mathrm{n}(\%)^{\ddagger}$ & $229(52.4)$ & $11(45.8)$ & $194(51.3)$ & $24(68.6)$ & 0.002 \\
\hline History of arterial events, $\mathrm{n}(\%)$ & $26(5.7)$ & $3(10.3)$ & $22(5.6)$ & $1(2.6)$ & 0.424 \\
\hline
\end{tabular}

$\ddagger 5.0 \%$ missing data.

$\mathrm{IQR}=$ Interquartile range.

* Chi-square tests or Fisher's exact tests when appropriate, were used for categorical variables and analysis of variance or Kruskal-Wallis tests for (non-)parametric continuous variables.

Table 2. Mortality and incident vascular events

\begin{tabular}{|c|c|c|c|c|c|}
\hline \multirow[t]{2}{*}{ Outcome } & \multirow[t]{2}{*}{ Total } & \multicolumn{3}{|c|}{$\mathrm{eGFR}, \mathrm{ml} / \mathrm{min} / 1.73 \mathrm{~m}^{2}$} & \multirow[t]{2}{*}{ p value* } \\
\hline & & $<60$ & $60-120$ & $>120$ & \\
\hline Death from any cause, $\mathrm{n}(\%)$ & $115(25.0)$ & $18(62.1)$ & $85(21.7)$ & $12(30.8)$ & $<0.001$ \\
\hline$<1$ month after event & $21(4.6)$ & $3(10.3)$ & $18(4.6)$ & 0 & $\mathrm{n} / \mathrm{a}$ \\
\hline$>1$ month after event & $94(20.4)$ & $15(51.7)$ & $67(17.1)$ & $12(30.8)$ & $<0.001$ \\
\hline Any vascular event, n (\%) & $98(21.3)$ & $11(37.9)$ & $82(20.9)$ & $5(12.8)$ & 0.048 \\
\hline Stroke (IS, ICH), n (\%) & $52(11.3)$ & $8(27.6)$ & $40(10.2)$ & $4(10.3)$ & 0.017 \\
\hline Other arterial events, $\mathrm{n}(\%)$ & $59(12.8)$ & $6(20.7)$ & $52(13.3)$ & $1(2.6)$ & 0.069 \\
\hline
\end{tabular}

* Chi-square tests were used to compare the number of deaths or events between eGFR categories. $\mathrm{n} / \mathrm{a}=\mathrm{Not}$ available.

case-fatalities. Fifty two patients (11.3\%) had suffered from a fatal or non-fatal recurrent stroke and 59 patients (12.8\%) from fatal or non-fatal other arterial events (table 2). Thirteen patients $(2.3 \%)$ had both a recurrent stroke and another arterial event. Thirty two patients $(61.5 \%)$ had their recurrent stroke at an age $<50$ years, 14 patients $(26.9 \%)$ between 50 and 60 years and only 6 patients $(11.5 \%)>60$ years.

Kidney Dysfunction and Outcome after Young Stroke
Kidney Dysfunction and Cumulative Risk of Mortality

The cumulative risk of mortality in patients with a low eGFR was significantly increased compared with the reference (log-rank $\mathrm{p}<0.001$; fig. 1$)$. The point estimate for the 15-year cumulative mortality was 70\% (95\% CI 4694) for patients with a low eGFR, $24 \%$ (95\% CI 18-30) for patients with a normal eGFR and 30\% (95\% CI 12-48) for patients with a high eGFR. Both a low eGFR (HR 4.6; 95\% 
CI 2.6-8.2) and a high eGFR (HR 2.6; 95\% CI 1.3-4.9) were associated with an increased risk of death after adjustment for age, gender and cardiovascular risk factors compared with the reference (table 3).

\section{Kidney Dysfunction and Cumulative Risk of Incident Stroke}

Cumulative risk of any incident vascular event in patients with a low eGFR was significantly increased compared with the reference adjusted for age, gender and cardiovascular risk factors (HR 2.5; 95\% CI 1.3-4.7). Incident vascular events can be divided in incident stroke and other vascular incident events. The cumulative risk of incident stroke in patients with a low eGFR was significantly increased compared with the reference $(\log$-rank $\mathrm{p}<$ 0.001 ). The point estimate for the 15 -year cumulative risk of incident stroke was $45 \%$ (95\% CI 16-74) for patients with a low eGFR, $13 \%$ (95\% CI 9-17) for patients with a normal eGFR and $8 \%(95 \%$ CI $0-18)$ for patients with a high eGFR (fig. 2a). The patients with a low eGFR were at increased risk for incident stroke (HR 4.1; 95\% CI 1.99.0) after adjustment for age, gender and cardiovascular risk factors.

\section{Kidney Dysfunction and Cumulative Risk of Incident}

\section{Other Vascular Events}

Cumulative risk of incident other vascular events in patients with a low eGFR was significantly increased compared with the reference $(\log$-rank $\mathrm{p}=0.017)$. The point estimate for the 15-year cumulative risk of incident other vascular events was $23 \%$ (95\% CI 3-43) for patients with a low eGFR, 17\% (95\% CI 11-23) for patients with normal eGFR and 3\% (95\% CI 0-9) for patients with a high eGFR. However, this effect was not statistically significant anymore after adjustment for age, gender and cardiovascular risk factors (HR 2.1; 95\% CI 0.9-5.0; fig. 2b).

\section{Stratification of Subgroups}

The associations found between kidney dysfunction and the risk of mortality, incident stroke and incident other vascular events were similar for IS patients separately, when all patients are stratified according to the time of their index event $(<1990,1990-2000,>2000)$ and when including patients of whom a creatinine level was available within 1 day after the index event $(n=284)$.

\section{Observed Compared to Expected Kidney Function}

Sixty four patients (13.9\%) had an observed eGFR $<\mathrm{p} 5$ of the expected eGFR of which 35 patients (54.7\%) had an eGFR $>60 \mathrm{ml} / \mathrm{min} / 1.73 \mathrm{~m}^{2}$, whereas 32 patients $(7.0 \%)$

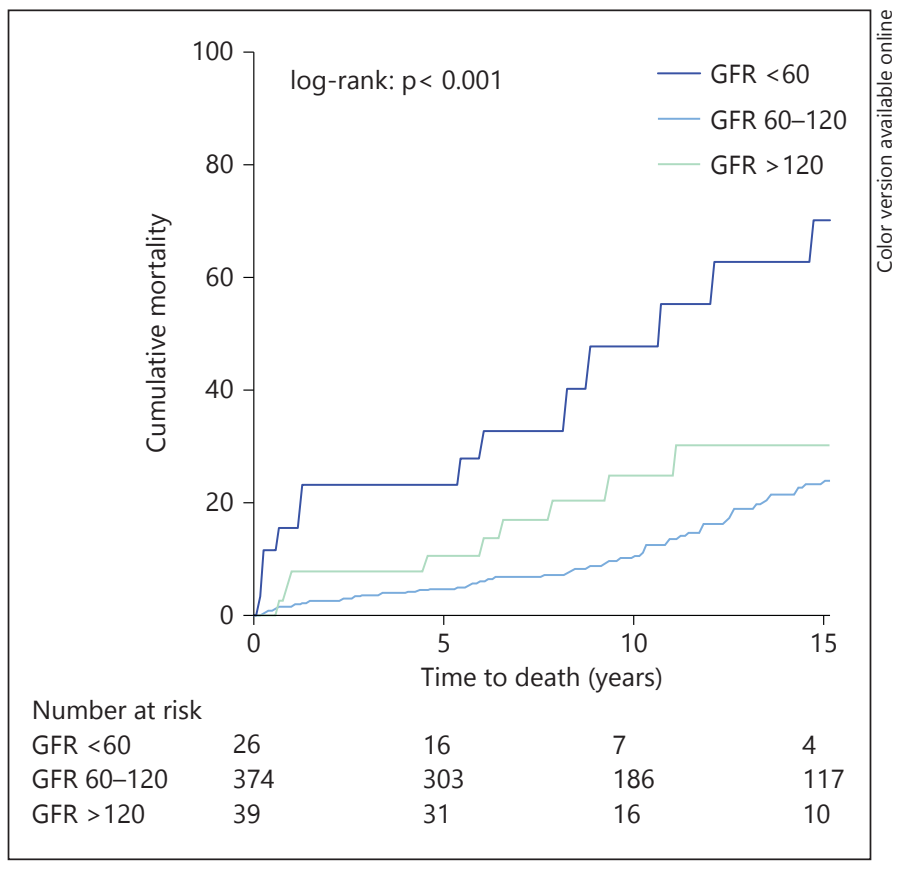

Fig. 1. Cumulative mortality.

Table 3. Risk of all-cause mortality and incident vascular events in patients with kidney dysfunction

\begin{tabular}{|c|c|c|c|c|}
\hline & \multicolumn{2}{|c|}{ eGFR $<60$} & \multicolumn{2}{|c|}{ eGFR > 120} \\
\hline & $\mathrm{HR}$ & $95 \% \mathrm{CI}$ & HR & $95 \% \mathrm{CI}$ \\
\hline Death from any cause & 4.6 & $2.6-8.2$ & 2.6 & $1.3-4.9$ \\
\hline Any vascular event & 2.5 & $1.3-4.7$ & $\mathrm{n} / \mathrm{a}^{*}$ & \\
\hline Stroke & 4.1 & $1.9-9.0$ & & \\
\hline Other arterial events & 2.1 & $0.9-5.0$ & & \\
\hline
\end{tabular}

Normal eGFR $\left(60-120 \mathrm{ml} / \mathrm{min} / 1.73 \mathrm{~m}^{2}\right)$ served as the reference group. Analysis was adjusted for gender, age and the presence of hypertension, diabetes mellitus and/or a history of arterial disease.

* $\mathrm{n} / \mathrm{a}=$ Not available; since the effect of an eGFR $>120 \mathrm{ml} /$ $\mathrm{min} / 1.73 \mathrm{~m}^{2}$ on the occurrence of incident events was not constant compared to the reference group, Cox proportional hazard analysis was not performed.

had an eGFR $>$ p95 of the expected eGFR. Seventeen patients $(43.6 \%)$ with an eGFR $>120 \mathrm{ml} / \mathrm{min} / 1.73 \mathrm{~m}^{2}$ did have an eGFR between $\mathrm{p} 5$ and $\mathrm{p} 95$. The cumulative risks of mortality and incident vascular events for patients with an eGFR $<$ p5, between p5 and p95 and $>$ p95 of the expected eGFR were similar to the risks of those patients with an eGFR $<60,60-120$ and $>120 \mathrm{ml} / \mathrm{min} / 1.73 \mathrm{~m}^{2}$, respectively. 


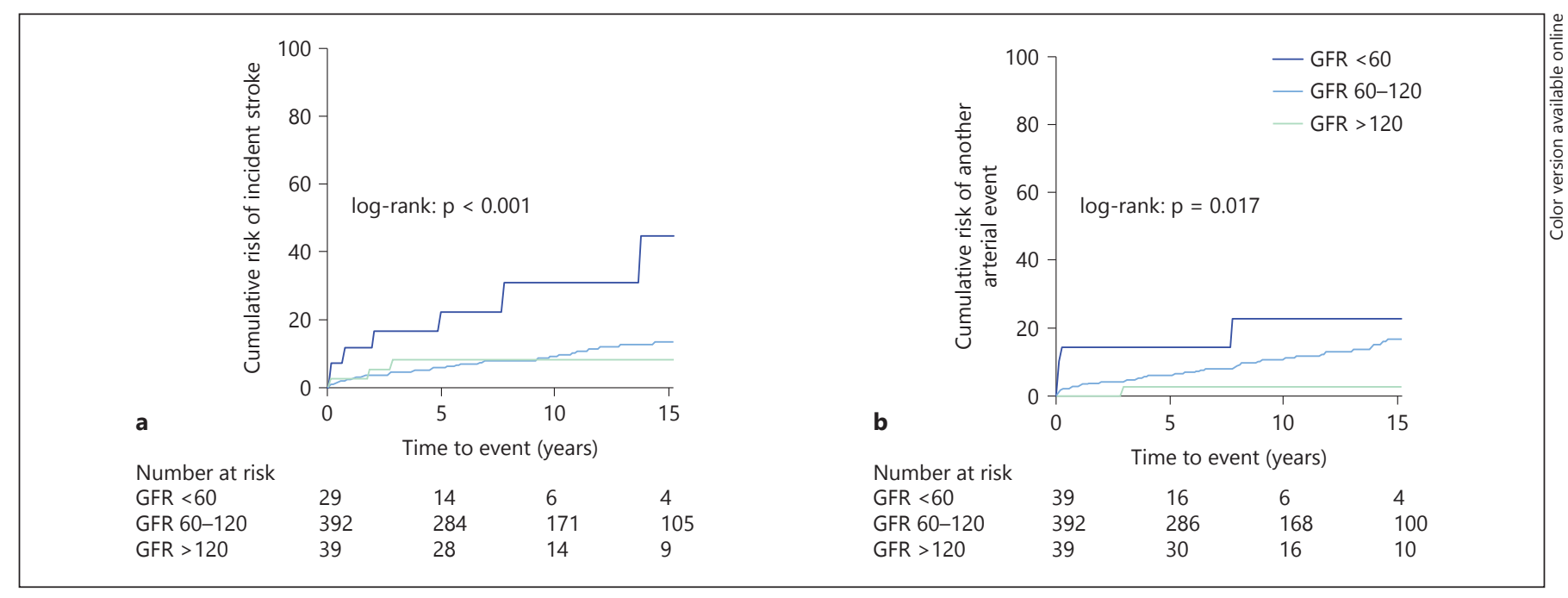

Fig. 2. Cumulative risk of incident events. a Cumulative risk of incident stroke. b Cumulative risk of another arterial event.

\section{Discussion}

We showed that young stroke patients with kidney dysfunction (eGFR $<60 \mathrm{ml} / \mathrm{min} / 1.73 \mathrm{~m}^{2}$ ) at baseline had a 15-year risk of death and recurrent stroke of 70 and $45 \%$, respectively. This risk was $4-5$ times increased compared to patients with an eGFR in the normal range, independent of co-occurring hypertension and/or diabetes mellitus. In contrast, there was no increased risk of other vascular events.

Strengths of our study were the prospective and singlecenter design, which allowed us to collect information systematically and uniformly both at baseline and followup, thereby reducing the risk of information bias. Furthermore, our study had one of the longest follow-up durations reported.

However, there are also some limitations. First, although baseline creatinine levels were available from $>70 \%$ of all participants, selection bias could have occurred. Baseline creatinine levels were most often missing in those who had their initial stroke longer ago. A higher proportion of incident vascular events was seen in these patients in comparison to participants ( 21 vs. $11 \%$ for incident stroke and 17 vs. $13 \%$ for other vascular events), while there was no difference in mortality. Also the 5-year risk of incident stroke was somewhat higher than expected in these patients ( $14 \%$ (no creatinine available) vs. $22 \%$ (eGFR <60); 6\% (eGFR 60-120); 8\% (eGFR >120)), suggesting that there is an overrepresentation of patients with an incident stroke among the patients of whom we did not have a creatinine level available.

Kidney Dysfunction and Outcome after Young Stroke
Second, information bias could have occurred by using creatinine levels up to 1 month after the event. Although it has been described that there can be some fluctuation in creatinine levels in the first days after an ICH [29], we considered it unlikely that this time-window would affect the creatinine levels substantially. As expected we found similar results when the analysis was limited to only those patients who had a creatinine level available within 1 day after stroke.

Furthermore, we are the first to relate the observed eGFR in our patients to the expected eGFR (defined by a healthy population) in an additional analysis, considering the age and gender of the patient to define poor kidney function. Thus, we controlled for misclassification of young patients with impaired kidney function who did have an eGFR $>60 \mathrm{ml} / \mathrm{min} / 1.73 \mathrm{~m}^{2}$ as having a normal kidney function. This additional analysis showed similar associations between poor kidney function and the risk of death and incident strokes.

Another possible cause of misclassification could be that the eGFR is based on only one creatinine measurement, which might not reflect true kidney dysfunction in all cases. In some patients, the decreased eGFR might be due to other factors like stroke and dehydration. However, the possible overestimation of the total number of patients having kidney dysfunction, would lead to an underestimation of the effect of kidney dysfunction on the endpoints.

Previous studies have shown a clear relationship between poor kidney function and mortality, albeit in an elderly stroke population. Only one previous study de-

Cerebrovasc Dis 2016;42:224-231 
scribed a similar relationship in young stroke patients; however, the mean follow-up was much shorter [30]. They described a relationship between mortality and an eGFR $<60 \mathrm{ml} / \mathrm{min} / 1.73 \mathrm{~m}^{2}$ and an eGFR $>120 \mathrm{ml} /$ $\mathrm{min} / 1.73 \mathrm{~m}^{2}$ and mortality similar to our results [9]. An increased eGFR $>120 \mathrm{ml} / \mathrm{min} / 1.73 \mathrm{~m}^{2}$ can be regarded as hyperfiltration, which could be a sign of early kidney disease [31]. However, a high eGFR can also be due to a low creatinine level caused by muscle wasting in patients with physical limitations after stroke (bedridden, wheel-chair bound). In these patients, increased mortality might be caused by comorbidity and might not be related to true kidney disease.

In the elderly population, kidney dysfunction has been independently associated with increased risk of incident cardiovascular events after stroke [31-33]. The previously mentioned study in young stroke patients also investigated the relationship between kidney dysfunction and incident arterial events in a young stroke population [9]. In contrast to our results, this association was not independent of cardiovascular risk factors. Very interestingly, we could not establish an association between kidney dysfunction and other vascular events independent of hypertension, diabetes mellitus and/or a history of vascular events. This suggests an additional pathophysiological mechanism underlying the association between kidney disease and incident stroke apart from traditional risk factors that does not affect other arteries. A possible explanation for the increased risk of incident stroke is that progressive kidney dysfunction triggers increased blood pressures through several pathophysiological mechanisms [34], possibly increasing the risk of stroke independent of the presence of hypertension at baseline. It can be speculated that the heart is less vulnerable to hypertension itself, while the brain and kidney share a similar vascular structure with low-resistance exposure of the small vessels to highly pulsatile flow and pressure [8]. Also, there are hypotheses that novel nontraditional risk factors, like chronic inflammation and oxidative stress are involved, affecting the cerebral microvasculature $[8,10]$.

In conclusion, kidney dysfunction at the time of a young stroke onset is related to an increased risk of longterm mortality and stroke recurrence, but not to incident cardiovascular disease. This warrants a more intensive follow-up of young stroke patients with signs of kidney dysfunction in the early phase. Probably kidney dysfunction is not only a risk factor for poor outcome (increased mortality and increased risk of incident strokes). But the clear association between kidney dysfunction and incident stroke seen in our young stroke population might be a first step in considering kidney dysfunction a new risk factor for the development of stroke at young age. Also, this finding can lead to the discovery of new insights in terms of the etiological differences between cardiovascular and cerebrovascular disease.

\section{Acknowledgments}

None.

\section{Disclosure Statement}

On behalf of all authors, the corresponding author states that there is no conflict of interest.

\section{Funding}

This study was funded by the Dutch Epilepsy Fund (grant number 10-18).

\section{Contributorship Statement}

N.E. Synhaeve: acquisition, analysis and interpretation of data and drafting the manuscript. M.E. van Alebeek: acquisition and interpretation of data and critical revision of the manuscript for intellectual content. R.M. Arntz and N.A.M. Maaijwee: acquisition of data and critical revision of the manuscript for intellectual content. L.C.A. Rutten-Jacobs and H.C. Schoonderwaldt: study concept and design, acquisition of data and critical revision of the manuscript for intellectual content. P.L.M. de Kort: critical revision of the manuscript for intellectual content. M.J. van der Vlugt: interpretation of data and critical revision of the manuscript for intellectual content. E.J. van Dijk: study concept and design, acquisition of data, analysis and interpretation of the data and critical revision of the manuscript for intellectual content. J.F.M. Wetzels: interpretation of the data and critical revision of the manuscript for intellectual content. F-E. de Leeuw: study concept and design, acquisition of data, analysis and interpretation of the data, drafting the manuscript, critical revision of the manuscript for intellectual content, obtaining funding and study supervision.

\section{References}

1 Ferro JM, Massaro AR, Mas JL: Aetiological diagnosis of ischaemic stroke in young adults. Lancet Neurol 2010;9:1085-1096.

2 Hsieh CY, Lin HJ, Sung SF, Hsieh HC, Lai EC, Chen $\mathrm{CH}$ : Is renal dysfunction associated with adverse stroke outcome after thrombolytic therapy? Cerebrovasc Dis 2014;37:51-56.

3 Toyoda K, Fujii K, Ando T, Kumai Y, Ibayashi S, Iida M: Incidence, etiology, and outcome of stroke in patients on continuous ambulatory peritoneal dialysis. Cerebrovasc Dis 2004;17:98-105. 
4 Hojs Fabjan T, Hojs R, Tetickovic E, Pecovnik Balon B: Ischaemic stroke - impact of renal dysfunction on in-hospital mortality. Eur J Neurol 2007;14:1351-1356.

5 Oksala NK, Salonen T, Strandberg T, Oksala A, Pohjasvaara T, Kaste M, Karhunen PJ, Erkinjuntti T: Cerebral small vessel disease and kidney function predict long-term survival in patients with acute stroke. Stroke 2010;41:1914-1920.

6 MacWalter RS, Wong SY, Wong KY, Stewart G, Fraser CG, Fraser HW, Ersoy Y, Ogston SA, Chen R: Does renal dysfunction predict mortality after acute stroke? A 7-year followup study. Stroke 2002;33:1630-1635.

7 Mostofsky E, Wellenius GA, Noheria A, Levitan EB, Burger MR, Schlaug G, Mittleman MA: Renal function predicts survival in patients with acute ischemic stroke. Cerebrovasc Dis 2009;28:88-94.

8 Toyoda K, Ninomiya T: Stroke and cerebrovascular diseases in patients with chronic kidney disease. Lancet Neurol 2014;13:823-833.

9 Putaala J, Haapaniemi E, Gordin D, Liebkind R, Groop PH, Kaste M, Tatlisumak T: Factors associated with impaired kidney function and its impact on long-term outcome in young ischemic stroke. Stroke 2011;42:2459-2464.

10 Sarnak MJ, Levey AS, Schoolwerth AC, Coresh J, Culleton B, Hamm LL, McCullough PA, Kasiske BL, Kelepouris E, Klag MJ, Parfrey P, Pfeffer M, Raij L, Spinosa DJ, Wilson PW; American Heart Association Councils on Kidney in Cardiovascular Disease, High Blood Pressure Research, Clinical Cardiology, and Epidemiology and Prevention: Kidney disease as a risk factor for development of cardiovascular disease: a statement from the American heart association councils on kidney in cardiovascular disease, high blood pressure research, clinical cardiology, and epidemiology and prevention. Hypertension 2003;42:1050-1065.

11 Rutten-Jacobs LC, Arntz RM, Maaijwee NA, Schoonderwaldt HC, Dorresteijn LD, van Dijk EJ, de Leeuw FE: Long-term mortality after stroke among adults aged 18 to 50 years. JAMA 2013;309:1136-1144.

12 Aho K, Harmsen P, Hatano S, Marquardsen J, Smirnov VE, Strasser T: Cerebrovascular disease in the community: results of a who collaborative study. Bull World Health Organ 1980;58:113-130.

13 Hatano S: Experience from a multicentre stroke register: a preliminary report. Bull World Health Organ 1976;54:541-553.

14 Boers GH, Smals AG, Trijbels FJ, Fowler B, Bakkeren JA, Schoonderwaldt HC, Kleijer WJ, Kloppenborg PW: Heterozygosity for homocystinuria in premature peripheral and cerebral occlusive arterial disease. N Engl J Med 1985;313:709-715.
15 Alberti KG, Zimmet PZ: Definition, diagnosis and classification of diabetes mellitus and its complications. Part 1: diagnosis and classification of diabetes mellitus provisional report of a WHO consultation. Diabet Med 1998; 15 : 539-553.

16 Rutten-Jacobs LC, Maaijwee NA, Arntz RM, Van Alebeek ME, Schaapsmeerders P, Schoonderwaldt HC, Dorresteijn LD, Overeem S, Drost G, Janssen MC, van Heerde WL, Kessels RP, Zwiers MP, Norris DG, van der Vlugt MJ, van Dijk EJ, de Leeuw FE: Risk factors and prognosis of young stroke. The FUTURE study: a prospective cohort study. Study rationale and protocol. BMC Neurol 2011;11:109.

17 Bousser MG, Amarenco P, Chamorro A, Fisher M, Ford I, Fox K, Hennerici MG, Mattle HP, Rothwell PM; PERFORM Study Investigators: Rationale and design of a randomized, double-blind, parallel-group study of terutroban $30 \mathrm{mg} /$ day versus aspirin $100 \mathrm{mg} /$ day in stroke patients: the prevention of cerebrovascular and cardiovascular events of ischemic origin with terutroban in patients with a history of ischemic stroke or transient ischemic attack (PERFORM) study. Cerebrovasc Dis 2009;27:509-518.

18 Brott T, Adams HP Jr, Olinger CP, Marler JR, Barsan WG, Biller J, Spilker J, Holleran R, Eberle R, Hertzberg V, et al: Measurements of acute cerebral infarction: a clinical examination scale. Stroke 1989;20:864-870.

19 Williams LS, Yilmaz EY, Lopez-Yunez AM: Retrospective assessment of initial stroke severity with the NIH stroke scale. Stroke 2000; 31:858-862.

20 Kasner SE, Chalela JA, Luciano JM, Cucchiara BL, Raps EC, McGarvey ML, Conroy MB, Localio AR: Reliability and validity of estimating the NIH stroke scale score from medical records. Stroke 1999;30:1534-1537.

21 Rutten-Jacobs LC, Maaijwee NA, Arntz RM, Schoonderwaldt HC, Dorresteijn LD, van der Vlugt MJ, van Dijk EJ, de Leeuw FE: Longterm risk of recurrent vascular events after young stroke: the FUTURE study. Ann Neurol 2013;74:592-601.

22 Wetzels JF, Kiemeney LA, Swinkels DW, Willems HL, den Heijer M: Age- and gender-specific reference values of estimated GFR in Caucasians: the Nijmegen biomedical study. Kidney Int 2007;72:632-637.

23 van den Brand JA, van Boekel GA, Willems HL, Kiemeney LA, den Heijer M, Wetzels JF: Introduction of the CKD-EPI equation to estimate glomerular filtration rate in a Caucasian population. Nephrol Dial Transplant 2011;26:3176-3181.

24 Lee D, Levin A, Roger SD, McMahon LP: Longitudinal analysis of performance of estimated glomerular filtration rate as renal function declines in chronic kidney disease. Nephrol Dial Transplant 2009;24:109-116.
25 Levey AS, Coresh J, Greene T, Stevens LA, Zhang YL, Hendriksen S, Kusek JW, Van Lente F; Chronic Kidney Disease Epidemiology Collaboration: Using standardized serum creatinine values in the modification of diet in renal disease study equation for estimating glomerular filtration rate. Ann Intern Med 2006; 145:247-254.

26 Coresh J, Astor BC, Greene T, Eknoyan G, Levey AS: Prevalence of chronic kidney disease and decreased kidney function in the adult US population: third national health and nutrition examination survey. Am J Kidney Dis 2003;41:1-12.

27 Adams HP Jr, Bendixen BH, Kappelle LJ, Biller J, Love BB, Gordon DL, Marsh EE 3rd: Classification of subtype of acute ischemic stroke. Definitions for use in a multicenter clinical trial. TOAST. Trial of Org 10172 in Acute Stroke Treatment. Stroke 1993;24:35-41.

28 Pocock SJ, Clayton TC, Altman DG: Survival plots of time-to-event outcomes in clinical trials: good practice and pitfalls. Lancet 2002; 359:1686-1689.

29 Rhoney DH, Parker D Jr, Millis SR, Whittaker $\mathrm{P}$ : Kidney dysfunction at the time of intracerebral hemorrhage is associated with increased in-hospital mortality: a retrospective observational cohort study. Neurol Res 2012; 34:518-521.

30 Steinicke R, Gaertner B, Grittner U, Schmidt W, Dichgans M, Heuschmann PU, Tanislav C, Putaala J, Kaps M, Endres M, Schmidt R, Fazekas F, Norrving B, Rolfs A, Martus P, Tatlisumak T, Enzinger C, Jungehulsing G): Kidney function and white matter disease in young stroke patients: analysis of the stroke in young Fabry patients study population. Stroke 2012;43:2382-2388.

31 Kuwashiro T, Sugimori H, Ago T, Kamouchi M, Kitazono T; FSR Investigators: Risk factors predisposing to stroke recurrence within one year of non-cardioembolic stroke onset: the Fukuoka stroke registry. Cerebrovasc Dis 2012;33:141-149.

32 Tsagalis G, Akrivos T, Alevizaki M, Manios E, Stamatellopoulos K, Laggouranis A, Vemmos KN: Renal dysfunction in acute stroke: an independent predictor of long-term all combined vascular events and overall mortality. Nephrol Dial Transplant 2009;24:194200.

33 Kamouchi M, Kumagai N, Okada Y, Origasa H, Yamaguchi T, Kitazono T: Risk score for predicting recurrence in patients with ischemic stroke: the Fukuoka stroke risk score for Japanese. Cerebrovasc Dis 2012;34:351357.

34 Ritz E, Adamczak M, Zeier M: Kidney and hypertension-causes. Update 2003. Herz 2003;28:663-667. 